Jurnal Keperawatan Silampari

Volume 5, Nomor 1, Desember 2021

e-ISSN: 2581-1975

p-ISSN: 2597-7482

DOI: https://doi.org/10.31539/jks.v5i1.2586

IDMEKRE

\title{
PENYULUHAN KESEHATAN MENGGUNAKAN MEDIA FLIPCHART MENINGKATKAN STIGMA POSITIF MASYARAKAT TENTANG ODHA
}

\author{
G. Nur Widya Putra ${ }^{1}$, Putu Agus Ariana ${ }^{2}$, Ni Luh Gede Melda Rosita ${ }^{3}$ \\ Sekolah Tinggi Ilmu Kesehatan Buleleng ${ }^{1,2,3}$ \\ widyaputra90@gmail.com ${ }^{1}$
}

\begin{abstract}
ABSTRAK
Penelitian ini bertujuan untuk mengetahui pengaruh penyuluhan kesehatan tentang HIV/AIDS dengan menggunakan media flipchart terhadap stigma masyarakat di Desa Munduk. Desain penelitian ini yaitu pra eksperimen dengan rancangan one group pre post test design. Hasil penelitian menunjukkan stigma responden sebelum diberikan penyuluhan kesehatan tentang HIV/AIDS menggunakan media flipchart, rata-rata memiliki stigma negatif yang tinggi tentang HIV/AIDS $(81,1 \%)$, sedangkan setelah diberikan penyuluhan kesehatan sebagian besar responden $(70,3 \%)$ memiliki stigma negatif yang rendah tentang HIV/AIDS. Hasil analisis bivariat menunjukkan p-value 0,005. Simpulan, penyuluhan kesehatan menggunakan media flipchart efektif untuk meningkatkan stigma positif tentang ODHA pada masyarakat di Desa Munduk, Kabupaten Buleleng.
\end{abstract}

Kata Kunci: ODHA, Penyuluhan Kesehatan, Stigma

\section{ABSTRACT}

This study aims to determine the effect of health education on HIV/AIDS using flipchart media on community stigma in Munduk Village. The design of this research is preexperimental with a one-group pre-post-test design. The results showed that the stigma of respondents before being given health education about HIV/AIDS using flipchart media, on average, had a high negative stigma about HIV/AIDS (81.1\%). After being given health counseling, most respondents (70.3\%) have a low negative stigma about HIV/AIDS. The results of the bivariate analysis showed a p-value of 0.005. In conclusion, health education using flipchart media effectively increases positive stigma about PLWHA in the community in Munduk Village, Buleleng Regency.

Keywords: PLWHA, Health Counseling, Stigma

\section{PENDAHULUAN}

Menurut Asfar \& Asnianiar (2018); Sartika et al., (2021) menyatakan bahwa penyuluhan kesehatan merupakan penyampaian informasi pendidikan kesehatan yang dilakukan dengan cara menyebarkan pesan, menanamkan keyakinan, sehingga masyarakat tidak hanya sadar, tahu dan mengerti, tetapi juga mau dan bisa melaksanakan suatu anjuran yang berkaitan dengan kesehatan. Adanya pemberian informasi yang baru tersebut, menimbulkan minat yang tinggi terhadap sesuatu. Dengan mendapatkan suatu informasi, dapat membantu seseorang untuk memperoleh pengetahuan yang baru sehingga menjadikan 
seseorang untuk mencoba dan menekuni suatu hal dan pada akhirnya diperoleh pengetahuan yang lebih mendalam.

Hal yang seharusnya dilakukan adalah dengan memberikan dukungan khususnya keluarga sehingga ODHA lebih merasa diterima baik di keluarga maupun di masyarakat. Hal ini penting untuk meningkatkan kualitas hidup ODHA. Penelitian yang dilakukan oleh Putra et al., (2021) menemukan bahwa kualitas hidup ODHA juga dapat dihubungkan dengan tingkat spiritualitas seseorang. Oleh karena itu pengembangan penyuluhan yang berbasis spiritualitas juga perlu dilakukan.

Hasil penelitian yang dilakukan oleh Egbe et al., (2020) menunjukan bentuk stigma yang dialami ODHA digosipkan 56,4\%, merasa malu 57,1\%, merasa bersalah $38,7 \%$, menyalahkan diri sendiri 46,0\%. Dapat disimpulkan ODHA dalam penelitian ini sangat terstigmanisasi. Stigma terkait HIV telah dikaitkan dengan kurangnya informasi yang tepat mengenai penyebaran penyakit, ketakutan, dan penilaian moral dari mereka yang hidup dengan penyakit tersebut (Egbe et al., 2020).

Stigma dipengaruhi oleh beberapa faktor seperti pengetahuan, pendidikan dan status ekonomi. Hasil penelitian yang dilakukan oleh Utami et al., (2020); Andri et al., (2020) menemukan bahwa terdapat berbagai faktor yang berhubungan dengan stigma, yaitu pengetahuan, persepsi, pendidikan, pekerjaan, sikap dan status ekonomi. Stigma masyakat terhadap HIV/AIDS masih sangat tinggi, hal ini menyebabkan penanggulangan HIV/AIDS menjadi tidak optimal (Sando \& Widodo, 2021).

Berdasarkan studi pendahuluan yang dilakukan pada tanggal 26 Januari 2021 di Desa Munduk. Hasil wawancara 10 responden diperoleh hasil 9 responden memiliki stigma terhadap penderita HIV/AIDS. Mereka menyatakan lebih menjaga jarak dengan penderita HIV/AIDS, merasa takut berteman dengan penderita HIV/AIDS, malu berteman dengan penderita HIV/AIDS, tidak mau berjabat tangan, tidak ingin bekerja bersama HIV/AIDS, tidak ingin berdekatan dengan keluarga penderita HIV/AIDS dan merasa penderita HIV/AIDS harus diasingkan. 1 responden tidak memiliki stigma terhadap penderita HIV/AIDS. Semua responden tidak pernah mengikuti penyuluhan tentang HIV/AIDS. Dari hasil tersebut disimpulkan bahwa masyarakat masih memiliki stigma terhadap penderita HIV/AIDS.

Penelitian tentang penyuluhan kesehatan pada pasien ODHA sudah pernah dilakukan, namun fokus penelitian ini adalah media yang digunakan adalah media flipchart dalam melakukan penyuluhan kesehatan.

\section{METODE PENELITIAN}

Desain penelitian ini adalah penelitian kuantitatif dengan menggunakan rancangan pra eksperimental, one grup pre-post-test design. Pemilihan sampel dilakukan dengan menggunakan purposive sampling, dengan jumlah sampel yang digunakan dalam penelitian ini adalah 37 responden. Sampel dalam penelitian ini adalah masyarakat di Desa Munduk, Kabupaten Buleleng, Bali. Adapun kriteria inklusi dalam penelitian ini adalah responden yang menandatangani inform concent, berusia 20 sampai 49 tahun, serta mengikuti sampai akhir proses penelitian.

Pelaksanaan penelitian ini dilakukan di Desa Munduk, Kabupaten Buleleng. Periode penelitian dilaksanakan pada bulan Maret 2021. Alat ukur yang digunakan untuk mengukur stigma responden adalah dengan menggunakan kuesioner stigma HIV/AIDS. Kuesioner pre-test digunakan untuk mengukur stigma masyarakat sebelum diberikan penyuluhan kesehatan tentang HIV/AIDS dengan menggunakan media flipchart dan kuesioner pos-test 
yang digunakan untuk mengukur stigma masyarakat sesudah diberikan penyuluhan kesehatan tentang HIV/AIDS dengan menggunakan media flipchart.

Setelah data terkumpul, kemudian dilakukan proses pengolahan data. Hasil pengujian terhadap normalitas data diperoleh bahwa data berdistribusi tidak normal sehingga menggunkaan statistik parametrik dengan menggunakan wilcoxon untuk mendapatkan nilai p-value nya.

\section{HASIL PENELITIAN}

Analisis Univariat

Karakteristik Responden Berdasarkan Umur

Tabel. 1

Karakteristik Responden

Berdasarkan Umur

\begin{tabular}{cccccc}
\hline $\mathrm{N}$ & Min & Maks & Mean & SD & $95 \%$ CI \\
\hline 37 & 20 & 50 & 37,03 & 9,694 & $33,79-40,26$ \\
\hline
\end{tabular}

Berdasarkan tabel 1 dapat dilihat bahwa rata-rata umur dari 37 responden penelitian ini adalah 37,03 tahun. Umur termuda adalah 20 tahun dan umur tertua adalah 50 tahun, dengan standar deviasi sebesar 9,694 tahun. Dari hasil estimasi interval dapat disimpulkan bahwa 95\% diyakini bahwa rata-rata umur responden di Desa Munduk, Kabupaten Buleleng adalah diantara 41,58 sampai dengan 47,52 tahun.

\section{Karakteristik Responden Berdasarkan Pekerjaan}

Tabel. 2

Karakteristik Responden

Berdasarkan Pekerjaan

\begin{tabular}{|c|c|c|}
\hline Pekerjaan & Jumlah & Persentase \\
\hline Tidak Bekerja & 9 & $24,3 \%$ \\
\hline Petani/Buruh & 22 & $59,5 \%$ \\
\hline Swasta & 6 & $16,2 \%$ \\
\hline Total & 37 & $100 \%$ \\
\hline
\end{tabular}

Berdasarkan tabel 2 dapat dilihat bahwa dari 37 responden, mayoritas responden yaitu 22 orang $(59,5 \%)$ bekerja sebagai petani dan buruh.

\section{Karakteristik Responden Berdasarkan Pendidikan}

Tabel. 3

Karakteristik Responden

Berdasarkan Pendidikan

\begin{tabular}{lccc}
\hline & Pekerjaan & Jumlah & Persentase \\
\hline SD & & 15 & $40 \%$ \\
SMP & 17 & $45,9 \%$ \\
SMA & & 5 & $13,5 \%$ \\
\hline & Total & 37 & $100 \%$ \\
\hline
\end{tabular}


Berdasarkan tabel 3 dapat dilihat bahwa dari 37 responden, distribusi frekuensi responden berdasarkan tingkat pendidikan menujukan mayoritas responden memiliki riwayat pendidikan SMP yaitu sebanyak 17 responden $(45,9 \%)$.

\section{Stigma Responden Sebelum Diberikan Intervensi}

Tabel. 4

Stigma Sebelum Diberikan

Intervensi

\begin{tabular}{lccc}
\hline & Stigma Negatif & Jumlah & Persentase \\
\hline Rendah & & 7 & $18,9 \%$ \\
Tinggi & Total & 30 & $81,1 \%$ \\
\hline \multicolumn{2}{c}{} & 37 & $100 \%$ \\
\hline
\end{tabular}

Berdasarkan tabel 4 dapat dilihat bahwa distribusi Stigma responden sebelum diberikan penyuluhan kesehatan tentang HIV/AIDS menggunakan media flipchart, rata-rata memiliki stigma negatif yang tinggi tentang HIV/AIDS $(81,1 \%)$.

\section{Stigma Responden Setelah Diberikan Intervensi}

Tabel. 5

Stigma Setelah Diberikan

Intervensi

\begin{tabular}{lccc}
\hline & Stigma Negatif & Jumlah & Persentase \\
\hline Rendah & & 26 & $70,3 \%$ \\
Tinggi & & 11 & $29,7 \%$ \\
\hline \multicolumn{2}{c}{ Total } & 37 & $100 \%$ \\
\hline
\end{tabular}

Berdasarkan tabel 5 menunjukkan bahwa setelah diberikan penyuluhan kesehatan sebagian besar responden (70,3\%) memiliki stigma negatif yang rendah tentang HIV/AIDS.

\section{Analisis Bivariat}

Tabel. 6

Hasil Analisis Pengaruh Penyuluhan Kesehatan terhadap Stigma

\begin{tabular}{|c|c|c|}
\hline Variabel & P value & $\mathrm{N}$ \\
\hline Stigma & & \\
\hline Pre-Post & 0.005 & 37 \\
\hline
\end{tabular}

Berdasarkan tabel 6 menunjukan bahwa nilai $\mathrm{p}$ hasil analisis menunjukkan nilai 0,005 $<0,05$ maka dapat diartikan bahwa terdapat pengaruh penyuluhan kesehatan tentang HIV/AIDS dengan menggunakan media flipchart terhadap stigma masyarakat di Desa Munduk. Hasil uji statistik didapatkan nilai 0,005, maka disimpulkan terdapat perbedaan yang signifikan antara stigma pada pengukuran pertama dengan stigma pada pengukuran kedua. 


\section{PEMBAHASAN}

\section{Karakteristik Responden}

Berdasarkan tabel 1 menunjukkan rata-rata umur responden adalah 37,03 tahun. Kategori umur ini merupakan kelompok usia produktif bila dikategorikan menurut World Health Organization (WHO). Pemahaman tentang HIV/AIDS perlu dilakukan untuk mengurangi stigma negatif pada masyarakat di usia produktif. Hal ini sangat penting karena pada usia produktif, masyarakat harus dibekali tentang permasalahan kesehatan khususnya HIV/AIDS. Dengan memahami konsep penyakit, diharapkan masyarakat produktif mampu melakukan pencegahan agar terhindar dari HIV/AIDS. Selain itu, stigma negatif masyarakat tentang HIV/AIDS akan menurun. Berdasarkan tabel 2 menunjukkan karakteristik responden berdasarkan pekerjaan.

Semua usia produktif pasti memiliki pekerjaan tetap. Secara geografis letak desa Munduk adalah di dataran rendah, sehingga aktifitas masyarakat cenderung sebagai petani dan buruh. Berdasarkan tabel 3 menunjukkan tingkat pendidikan responden. Dapat dilihat bahwa dari 37 responden, distribusi frekuensi responden berdasarkan tingkat pendidikan menujukan mayoritas responden memiliki riwayat pendidikan SMP. Pendidikan yang rendah akan mempengaruhi stigma masyarakat tentang HIV/AIDS.

Hasil penelitian ini sejalan dengan penelitian yang dilakukan oleh Utami et al., (2020) yang meneliti tentang faktor-faktor yang mempengaruhi stigma adalah pengetahuan dan pekerjaan. Faktor-faktor lainnya yang juga berhubungan dengan stigma adalah persepsi, sikap, dan status ekonomi. Namun yang paling besar pengaruhnya terhadap stigma pada ODHA adalah pengetahuan. Dengan demikian penyuluhan yang dilakukan sebagai upaya promosi kesehatan tentang HIV/AIDS bermanfaat untuk memberikan pemahaman kepada masyarakat bahwa yang harus dihindari pada ODHA adalah virusnya, bukan penderitanya.

Berdasarkan tabel 4 dapat dilihat bahwa distribusi stigma responden sebelum diberikan penyuluhan kesehatan tentang HIV/AIDS menggunakan media flipchart, memiliki stigma negatif yang tinggi. Hal ini akan berdampak pada upaya penanggulangan terhadap HIV/AIDS. Ada beberapa penyebab tingginya stigma negatif seseorang tentang ODHA. Hasil penelitian ini sejalan dengan penelitian yang dilakukan oleh Sando \& Widodo (2021) yang menunjukkan bahwa stigma negatif masyarakat tentang ODHA masih cukup tinggi. Hal ini berarti bahwa penyuluhan-penyuluhan yang dilakukan belum efektif. Oleh karena itu diperlukan optimalisasi kegiatan penyuluhan serta upaya kerjasama lintas sektoral. Dengan demikian upaya penyuluhan dengan metode lainnya sangat diperlukan.

Berdasarkan tabel 5 dapat dilihat bahwa distribusi stigma responden setelah diberikan penyuluhan kesehatan tentang HIV/AIDS menggunakan media flipchart, memiliki stigma negatif yang rendah. Peneliti tertarik menggunakan media flipchart karena media ini mudah dalam penggunaannya, selain itu masyarakat juga lebih mudah dalam memahami informasi yang diberikan. Hal ini penting untuk menurunkan stigma negatif yang ada di masyarakat tentang HIV/AIDS. Hasil penelitian ini sejalan dengan penelitian yang dilakukan oleh Didi et al., (2020) yang menyarankan agar tidak mendiskriminasi terhadap ODHA. Hal yang seharusnya dilakukan adalah dengan memberikan dukungan khususnya keluarga sehingga ODHA lebih merasa diterima baik di keluarga maupun di masyarakat. Hal ini penting untuk meningkatkan kualitas hidup ODHA. Penelitian yang dilakukan oleh Putra et al., (2021) menemukan bahwa kualitas hidup ODHA juga dapat dihubungkan dengan tingkat spiritualitas seseorang. Oleh karena itu pengembangan penyuluhan yang berbasis spiritualitas juga perlu dilakukan. 


\section{Analisis Bivariat}

Berdasarkan tabel 6 menunjukan bahwa terdapat perbedaan yang signifikan antara stigma pada pengukuran pertama dengan stigma pada pengukuran kedua. Terdapat penurunan stigma negatif masyarakat tentang HIV/AIDS setelah diberikan penyuluhan dengan media flipchart HIV/AIDS. Oleh karena itu diperlukan upaya aktif untuk melakukan penyuluhan-penyuluhan terkait dengan stigma.

Hasil penelitian ini sejalan dengan penelitian yang dilakukan oleh Asfar \& Asnianiar (2018) yang memberikan penyuluhan menggunakan media leaflet. Hasil penelitiannya menunjukkan penyuluhan kesehatan memberikan pengaruh signifikan terhadap sikap remaja tentang penyakit HIV/AIDS. Penelitian lainnya yang dilakukan oleh Liu et al., (2020) dengan melakukan penelitian pada LSL yang ada di China. Hasil penelitiannya merekomendasikan sosialiasi tentang stigma yang dilakukan melalui media-media sosial, serta promosi yang dilakukan melalui penyuluhan juga bisa menjadi pendekatan yang menjanjikan.

\section{SIMPULAN}

Stigma masyarakat sebelum diberikan intervensi berupa penyluhan dengan media flipchart didapatkan rata-rata 30 orang dengan stigma tinggi. Stigma masyarakat sesudah diberikan intervensi berupa penyluhan dengan media flipchart didapatkan 26 orang dengan stigma rendah. Kesimpulan dalam penelitian adalah ada pengaruh penyuluhan kesehatan tentang HIV/AIDS dengan menggunakan media flipchart terhadap stigma masyarakat di Desa Munduk.

\section{SARAN}

Hasil penelitian ini diharapkan dapat dijadikan acuan dalam pengembangan model intervensi keperawatan, khususnya yang berhubungan dengan hasil penelitian ini dapat digunakan sebagai dasar dalam memberikan alternatif penyuluhan menggunakan media flipchart guna menurunkan stigma yang terjadi di kalangan masyarakat. Selain itu, Hasil yang didapatkan dalam penelitian ini dapat menambah wawasan serta rujukan untuk melakukan penelitian selanjutnya dengan jumlah sampel yang lebih besar dan pengembangan flipchart berbasis kearifan budaya lokal.

\section{DAFTAR PUSTAKA}

Andri, J., Ramon, A., Padila, P., Sartika, A., \& Putriana, E. (2020). Pengalaman Pasien ODHA dalam Adaptasi Fisiologis. Journal of Telenursing (JOTING), 2(2), 127-141. https://doi.org/https://doi.org/10.31539/joting.v2i2.1397

Asfar, A., \& Asnianiar, W. O. S. (2018). Pengaruh Penyuluhan Kesehatan terhadap Tingkat Pengatahuan dan Sikap tentang Penyakit HIV/AIDS di SMP Baznas Provinsi Sulawesi Selatan. Journal of Islamic Nursing, 3, 26-31. https://doi.org/https://doi.org/10.24252/join.v3i1.5471

Didi, A., Manurung, I. F. E., \& Sir, A. B. (2020). Pengetahuan dan Stigma Keluarga ODHA Terhadap Orang yang Terinfeksi HIV dan AIDS di Kota Kupang. Journal of Health $\begin{array}{llll}\text { and Behavioral } & \text { Science, }\end{array}$ https://doi.org/https://doi.org/10.35508/jhbs.v2i1.2111

Egbe, T. O., Nge, C. A., Ngouekam, H., Asonganyi, E., \& Nsagha, D. S. (2020). Stigmatization among People Living with HIV/AIDS at the Kumba Health District, Cameroon. Journal of the International Association of Providers of AIDS Care, 19, 1-7. https://doi.org/10.1177/2325958219899305 
Liu, C., Zhang, Y., Pan, S. W., Cao, B., Ong, J. J., Fu, H., \& Wu, D. (2020). Anticipated HIV Stigma Among HIV Negative Men Who Have Sex With Men in China: a crosssectional study. BMC Infectious Diseases, 1-9. https://bmcinfectdis.biomedcentral.com/articles/10.1186/s12879-020-4778-5

Putra, G. N. W., Ariana, P. A., Aryawan, K. Y., \& Putra, I. G. P. (2021). Spiritualitas Berhubungan dengan Kualitas Hidup ODHA. Journal of Telenursing (JOTING), 3(1), 155-162. https://doi.org/https://doi.org/10.31539/joting.v3i1.2110

Sando, W., \& Widodo, M. D. (2021). Analisis Faktor yang Mempengaruhi Penanggulangan HIV/AIDS di UPT Puskesmas Sungai Pakning Kabupaten Bengkalis Tahun 2020. Journal of Hospital Management and Health Sciences, 2(1). http://journal.almatani.com/index.php/jhmhs/article/view/95

Sartika, A., Oktarianita, O., \& Padila, P. (2021). Penyuluhan terhadap Pengetahuan Remaja tentang PKPR. Journal of Telenursing (JOTING), 3(1), 171-176. https://doi.org/https://doi.org/10.31539/joting.v3i1.2192

Utami, W. N., Hutami, M. S., Hafidah, F., \& Pristya, Y. R. (2020). Faktor-Faktor yang Berpengaruh terhadap Stigma dan Diskriminasi kepada ODHA: Systematic Review. Prosiding Forum Ilmiah Tahunan IAKMI, 25-26. http://jurnal.iakmi.id/index.php/Fitiakmi/article/view/68 